\title{
Analisis Pengaruh Website Quality terhadap Kepuasan Pengguna dengan Menggunakan Metode WebQual 4.0
}

\author{
Kenny Roz \\ Fakultas Ekonomi dan Bisnis, Universitas Muhammadiyah Malang, Indonesia \\ firdauskenny@umm.ac.id
}

\begin{abstract}
Online business competition requires business people who are able to improve the quality of the website to win market share. WebQual is a method developed by Barnes and Vidgen that measures website quality based on usability, information quality, and service interaction. This study aims to examine and analyze the effect of website quality on Traveloka's online booking site on user satisfaction. This research uses a quantitative approach with multiple regression analysis. Sampling uses a purposive sampling that is students in the city of Malang who have made online reservations on the Traveloka site with a sample of 186 respondents. Based on the results of data analysis found that: 1) usability has a positive and significant effect on user satisfaction, 2) information quality has a positive and significant effect on user satisfaction, and 3) the quality of service interactions has a positive and significant effect on user satisfaction
\end{abstract}

Keywords: User Satisfaction, Website Quality, WebQual 4.0

\section{PENDAHULUAN}

Internet merupakan kebutuhan yang tidak dapat dipisahkan dengan kehidupan sehari-hari. Seiring meningkatnya teknologi yang semakin canggih, pengguna internet di dunia saat ini memudahkan siapa saja untuk melakukan kegiatan bisnis. Tingginya animo masyarakat akan internet membuat para pelaku bisnis dapat menawarkan produknya baik berupa barang ataupun jasa. Untuk mempermudah menawarkan produkya, para pelaku bisnis memanfaatkan adanya website untuk menyampikan informasi berkaitan barang yang akan dijual kepada calon konsumen. Di Indonesia pertumbuhan penggunaan Internet mengalami kenaikan dari tahun ke tahun. Berdasarkan data Asosiasi Penyelenggara Jasa Internet ®n@i@(APII), di tahun 2018 pengguna

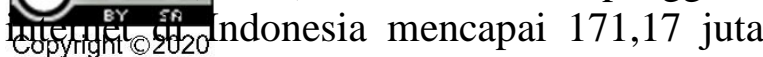
meningkat $10,16 \%$ dari tahun sebelumnya sebesar 143,26 juta. Hal ini membuktikan begitu pesatnya perkembangan pengguna internet di negeri ini.

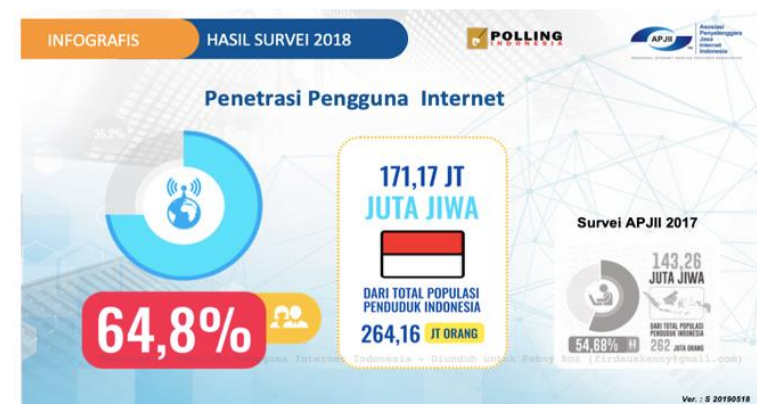

Gambar 1 : Pertumbuhan Pengguna Internet di Indonesia

Sumber : www.apjii.or.id (2019)

Website merupakan suatu bentuk layanan dalam sebuah jaringan internet yang berisikan informasi yang dapat diakses siapapun, kapanpun dan dimanapun. Website yang baik adalah Website yang 
memiliki informasi yang dapat memenuhi kebutuhan user atau pengguna. (C.-L. Hsu, Chang, \& Chen, 2012) mengungkapkan kualitas website merupakan sebuah instrumen untuk mengukur dan menilai kegunaan, fungsi dan kualitas interaksi jasa dari website internet.

Keberhasilan perusahaan atau organisasi dalam memenuhi kebutuhan konsumen adalah capaian kepuasan yang dirasakan oleh pengguna atau konsumen. Sering terjadi permasalahan antara penyedia jasa dan user akhir (Ariani, 2009). Ketidakpuasan sering terjadi akibat ketidakpahaman penyedia jasa akan kebutuhan dan keinginan dari konsumen. Menurut (Tjiptono, 2017) kualitas layanan website memberikan pengaruh yang besar terhadap pengguna layanan itu sendiri.

Semakin tinggi kualitas dari suatu website maka akan semakin banyak user atau pengguna yang akan mengakses Website tersebut. Penelitian yang dilakukan (Noronha \& Rao, 2017) membuktikan bahwa kualitas Website memberikan efek yang besar terhap kepuasan pelanggan dalam pencarian informasi. User selalu mencari informasi sedetail mungkin sebelum memilih dan menentukan barang yang akan dibeli. Hal ini juga diperkuat oleh (Tatang, 2017) bahwa kualitas website yang baik memberikan pengaruh puas yang dirasakan serta menimbulkan persepsi untuk melakukan pembelian ulang dan tidak pindah kepada penyedia jasa yang sejenis.

Traveloka merupakan salah satu perusahaan yang berbasis teknologi yang menyediakan layanan tiket pesawat, reservasi hotel, dan pembayaran secara online yang terintegrasi kedalam satu system dengan mekanisme perbandingan harga antar maskapai yang memudahkan pelanggannya untuk memilih maskapai yang ideal bagi mereka dan metode pembayaran yang beragam. Di Indonesia Traveloka merupakan travel agent yang paling diminati oleh masyarakat.
Tabel 1. Traffic Metric Online Travel Agent di Indonesia

\begin{tabular}{lccc}
\hline Nama & $\begin{array}{c}\text { Peringkat di } \\
\text { Indoensia }\end{array}$ & $\begin{array}{c}\text { Total } \\
\text { pengunjung }\end{array}$ & $\begin{array}{c}\text { Rata-rata } \\
\text { Durasi } \\
\text { Pengunjung }\end{array}$ \\
\hline Traveloka & 68 & 21.42 Juta & 3,55 \\
Tiket.com & 148 & 5,67 Juta & 3,26 \\
Booking.com & 137 & 5.23 Juta & 7.31 \\
Pegi-Pegi & 183 & 4.42 Juta & 3.55 \\
\hline
\end{tabular}

Sumber : www.similarweb.com (2019)

Berdasarkan tabel 1 data traffic metric di Indonesia yang dikutip dari www.similarweb.com tahun 2019, Traveloka menduduki peringkat pertama di Indonesia di sektor online travel agent dengan total jumlah pengunjung sebsear 21.42 juta, ratarata durasi pengunjung sebesar 3,55 menit dan rata-rata tiap halaman sebesar 3,41. Disusul peringkat berikutnya adalah Tiket.com, Booking.com dan Pegi-pegi. Berdasar penjelasan di atas, menarik untuk dilakukan penelitian terkait kualitas website pada travel agent Traveloka yang dibuat untuk memuaskan pelanggan dan memberikan solusi dari permasalahan yang sedang dihadapi seperti kebutuhan pemesanan tiket pesawat atau hotel baik di dalam maupun di luar negeri.

\section{Website Quality}

World Wild Web atau yang lebih dikenal dengan website merupakan sebuah sistem dengan protokol yang diterima secara universal untuk menyimpan, mengambil, memformat, dan menampilkan informasi melalui arsitektur computer client ataupun server. Menurut (Raharjo, 2011), website adalah suatu bentuk layanan dalam sebuah jaringan internet yang berisikan informasi yang dapat diakses siapapun, kapanpun dan dimanapun. Website yang baik adalah website yang memiliki informasi yang dapat memenuhi kebutuhan user atau pengguna. (C. Hsu, Chang, \& Chen, 2012) mengungkapkan kualitas website merupakan sebuah instrumen untuk mengukur dan menilai kegunaan, fungsi dan kualitas interaksi jasa dari website internet. Kualitas website (WebQual) merupakan salah satu metode pengukuran kualitas website 
berdasarkan persepsi pengguna akhir. WebQual merupakan pengembangan dari ServQual yang telah banyak digunakan untuk pengukuran kualitas jasa.

Menurut (Barnes \& Vidgen, 2002) WebQual dibentuk berdasarkan 3 kriteria yaitu usability, information quality dan service interaction quality. Usability merupakan tingkat kualitas dari sistem yang mudah dipelajari atau dikenali, mudah digunakan dan mendorong pengguna untuk menggunakan sistem sebagai alat bantu positif dalam menyelesaikan permasalahan yang sedang dihadapi. Informasi dalam sebuah website sangat penting sebagai salah satu instrumen dalam penyajian website yang baik.

Information quality berhubungan terhadap kualitas dari konten website yaitu kepantasan informasi bagi tujuan pengguna, misalnya mengenai akurasi, format dan relevansi dari informasi yang disajikan. Dalam penelitian ini dimensi kualitas informasi memberikan pengaruh yang baik kepada pengguna. Hal lain yang penting dalam kualitas website adalah service interaction. Service intercation merupakan bentuk interaksi layanan yang dirasakan pengguna ketika terlibat secara mendalam dengan website. Ketika seorang pengguna atau user terlibat langsung dengan website yang sedang diakses jelas memberikan keterikatan yang mendalam antara website dan pengguna.

\section{Kepuasan Pengguna}

Kepuasan merupakan perasaan seseorang dapat berupa rasa senang atau kecewa dari kinerja atau hasil suatu produk yang telah dirasakan (Kotler, Philip, Amstrong, 2008). (Lovelock, 2007) menyatakan bahwa kepuasan adalah keadaan emosional, sesuatu yang dirasakan pasca pembelian atau berinteraksi dengan penyedia produk dapat berupa kemarahan, ketidakpuasan, kejengkelan, kegembiraan dan kesenengan. Penelitian yang dilakukan oleh (Behera, 2018) mengungkapkan bahwa kepuasan pelanggan merupakan aspek terpenting dalam sebuah organisasi dimana organisasi tersebut akan mendaptkan keuntungan jika dapat memeliharanya dengan baik. Kepuasan dipengaruhi oleh perbandingan layanan yang dipahami dengan pelayanan yang diharapkan, dan sebagai reaksi emosional jangka pendek pelanggan terhadap kinerja pelayanan tertentu.

\section{Kerangka Konseptual}

Dalam penelitian ini variabel-variabel yang akan dianalisis dibedakan menjadi dua yaitu variabel bebas, dan variabel terikat. Variabel bebas atau independent variable diwakili oleh website quality dan variabel terikat atau dependent variable dalam penelitian ini adalah kepuasan pengguna. Kerangka konseptual dalam penelitian ini dapat dilihat pada gambar berikut :

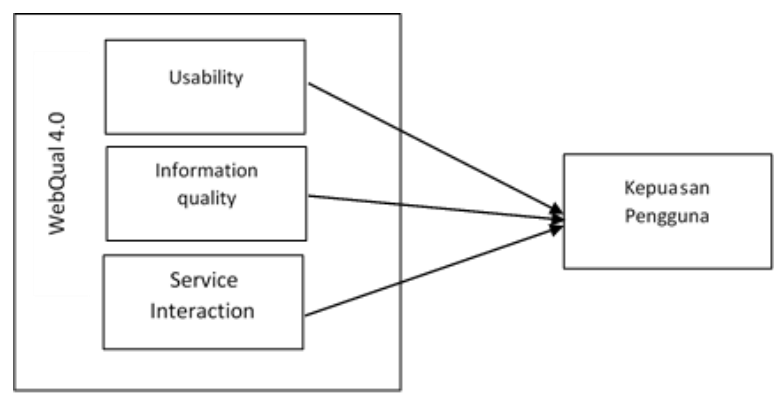

Gambar 2 : Kerangka Konseptual Regresi Linear Berganda

\section{Pengaruh Usability terhadap Kepuasan Pengguna}

Penelitian (Liang \& Chen, 2009) mengungkapkan usability website merupakan kemudahan pengguna dalam memproses dan mengakses ketersediaan, fleksibilitas, keandalan, dan waktu respons. Temuan hasil penelitian ini diperkuat (Muhsin \& Zuliestiana, 2017) menyatakan usability memberikan rasa kepuasan terhadap para pengunjung situs yang sedang diteliti. Rasa puas muncul ketika kualitas website yang dikunjungi memenuhi persepsi dan harapan user atau pengguna. Berdasar hal tersebut maka hipotesis pertama dalam penelitian ini adalah:

$\mathrm{H}_{1}$ : Usability mempunyai pengaruh signifikan terhadap kepuasan pengguna 
Pengaruh Information Quality terhadap Kepuasan Pengguna

Penelitian (Khai, 2018) menjelaskan bahwa kualitas informasi sebuah website tidak hanya memberikan rasa puas kepada pengguna, tetapi juga memberikan keloyalan pengguna terhadap situs yang diakses. Semakin baik kualitas informasi yang dimiliki oleh sebuah website semakin tinggi tingkat kepuasan yang dirasakan oleh pengguna website tersebut. Berdasar hal tersebut maka hipotesis kedua dalam penelitian ini adalah:

$\mathrm{H}_{2}$ : Information quality mempunyai pengaruh signifikan terhadap kepuasan pengguna

\section{Pengaruh Service Interaction Quality terhadap Kepuasan Pengguna}

Penelitian (Manasra, Zaid, \& Taher Qutaishat, 2013) menjelaskan bahwa salah satu hal yang terpenting dalam memenuhi rasa puas seorang pengguna adalah bentuk interaksi layanan yang diberikan oleh penyedia website. Temuan hasil penelitian ini juga diperkuat (Ardi \& Yulisetiarini, 2018) dengan adanya interaksi yang baik memberikan pengaruh yang baik kepada pengguna. Berdasar hal tersebut maka hipotesis ketiga dalam penelitian ini adalah:

$\mathrm{H}_{3}$ : Service Interaction Quality mempunyai pengaruh signifikan terhadap kepuasan pengguna

\section{METODE}

Penelitian ini merupakan penelitian kuantitatif ekplanatori yang didasarkan pada teori atau hipotesis untuk menguji suatu fenomena yang terjadi (Cooper, P, Schindler, 2014). Teknik pengambilan data primer menggunakan kuesioner secara langsung kepada responden. Daftar pertanyaan yang diajukan meliputi item-item variable website quality dan kepuasan pengguna.

\section{Populasi dan Sampel}

Populasi penelitian ini merupakan mahasiswa yang sedang berkuliah di Kota Malang. Tahap selanjutnya adalah pengambilan sampel. Pengambilan sampel dalam penelitian ini menggunakan Teknik purposive sampling dengan kriteria mahasiswa yang pernah menggunakan Traveloka. Menurut (Hair et al., 2014), penentuan jumlah sampel penelitian dapat dilakukan dengan melihat banyaknya jumlah variable yang diteliti. Lebih lanjut (Hair et al., 2014) menjelaskan bahwa penetapan jumlah sampel minimal dengan variabel $\leq 5$ maka jumlah sampel yang harus dipenuhi sebesar 100. Total responden dalam penelitian ini sebesar 186 dengan kriteria yang sebelumnya sudah ditentukan oleh peneliti.

\section{Teknik Pengumpulan Data}

Pengumpulan data yang digunakan dalam penelitian ini menggunakan kuesioner. Kuesioner disebar langsung kepada responden. Kuesioner dibuat menggunakan pernyataan-pernytaaan yang terstruktur dengan bahasa yang mudah dipahami dan dimengerti oleh responden. Daftar pernyataan berkaitan dengan item-item variable website quality dan kepuasan pengguna. Adapun persamaan regresi adalah sebagai berikut :

$$
\begin{aligned}
& \hat{\mathrm{Y}}=\mathrm{a}+\mathrm{B} 1 \mathrm{X} 1+\mathrm{B} 2 \mathrm{X} 2+\mathrm{B} 3 \mathrm{X} 3+\mathrm{e} \\
& \text { dengan } \\
& \mathrm{X}_{1} \quad=\text { keterangan : } \\
& \mathrm{X}_{2} \quad=\text { information quality } \\
& \mathrm{X}_{3} \quad=\text { service interaction } \\
& \mathrm{e} \quad=\text { eror } \\
& \hat{\mathrm{Y}} \quad=\text { kepuasan pengguna }
\end{aligned}
$$

B1,2,3 = koefisien regresi

\section{Definisi Operasional}

Definisi operasional variabel ditunjukkan untuk menyusun variable dalam penelitian ini. Terdapat 2 variabel yaitu independen dan dependen. Penelitian ini menggunkan skala likert 5 titik (sangat tidak setuju, tidak setuju, netra/ragu-ragu, setuju, dan sangat setuju). Skala Likert merupakan skala yang digunakan untuk menunjukkan tingkat kesetujuan terhadap setiap pernyataan yang diajukan dalam instrumen penelitian (Cooper, P, Schindler, 2014). Adapun definisi operasional yang digunakan dalam 
penelitian ini adalah: 1) Dimensi WebQual 4.0 (Barnes \& Vidgen, 2002): (a) Usability, (b) Information quality, (c) Service Interaction; 2) Dimensi Kepuasan Pengguna (Kotler, Philip, Amstrong, 2008) yaitu: (a) Pembelian ulang, (b) Mengatakan hal-hal yang baik tentang perusahaan kepada orang lain, (c) Merekomendasikannya (word of mouth), (d) Kurang memperhatikan merek dan iklan produk pesaing, (e) Membeli produk lain dari perusahaan yang sama, (f) Menawarkan ide produk atau jasa kepada perusahaan atau orang lain.

\section{HASIL DAN PEMBAHASAN Karakteristik Responden}

Tabel 2. Karakteristik Responden

\begin{tabular}{lcc}
\hline \multicolumn{1}{c}{ Keterangan } & Jumlah \\
\hline Jenis Kelamin & Pria & 71 \\
& Wanita & 115 \\
Usia & $18-21 \mathrm{Thn}$ & 175 \\
& $22-25 \mathrm{Thn}$ & 10 \\
Intensitas Pengguna & $>25 \mathrm{Thn}$ & 1 \\
& $1 \mathrm{kali}$ & 5 \\
& $2-4 \mathrm{kali}$ & 79 \\
& $>5 \mathrm{kali}$ & 102 \\
\hline
\end{tabular}

Sumber : Data primer diolah (2019)

Berdasarkan tabel 2 menunjukkan sebagian besar responden berjenis kelamin wanita, berusia rata-rata 18 s.d. 21 dan intensitas menggunakan Traveloka lebih dari 5 kali.

\section{Statistik Deskriptif Responden}

Setelah dilakukan identifikasi karakteristik responden, maka selanjutnya dilakukan tabulasi data yang disajikan dalam bentuk tabel 3 dibawah ini :

Tabel 3. Statistik Deskriptif Responden

\begin{tabular}{lcc}
\hline \multicolumn{1}{c}{ Variabel } & Mean & $\begin{array}{c}\text { Standart } \\
\text { Dev. }\end{array}$ \\
\hline Usability & 4,0351 &, 91138 \\
Information Quality & 3,8772 &, 96064 \\
Service Interaction & 3,9825 & 1,00426 \\
Kepuasan Pengguna & 3,9298 &, 88966 \\
\hline Sumber : Data primer diolah (2019)
\end{tabular}

Berdasarkan tabel 3 di atas menunjukkan nilai mean tertinggi terdapat pada variabel usability 4.0351 sedangkan nilai mean terendah terdapat pada variabel information quality sebesar 3.8772. Dari penjelasan tersebut dapat disimpulkan responden sebagian besar menilai bahwa variabel yang di uji masuk kedalam kategori baik.

\section{Uji Asumsi Klasik}

Uji normalitas digunakan untuk menguji pada model regresi antar variabel penganggu (residual) yang tergolong dalam ditribusi normal, Ada beberapa cara untuk melakukan uji normalitas, salah satunya adalah dengan melakukan analisis grafik normal probability plot dimana untuk membandingkan distribusi kumulatif dan distribusi normal. Data dikatakan normal akan membentuk garis lurus mengikuti garis diagonal yang ada, dan plotting data residual akan dibandingkan dengan garis diagonal. (Ghozali, 2012)

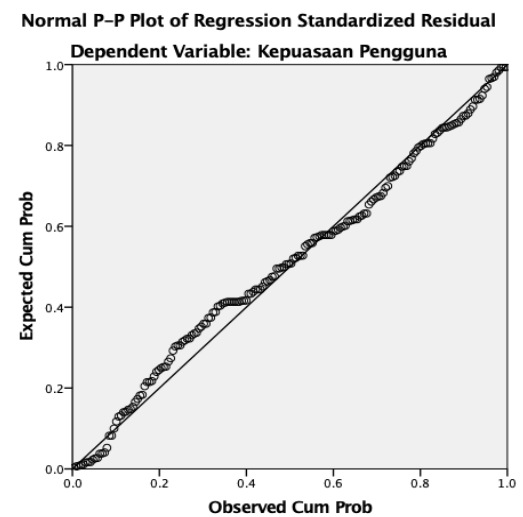

Gambar 3 : Hasil Uji Normalitas Sumber : Data primer diolah (2019)

Berdasarkan gambar 3 hasil pengujian dari penelitian ini terdapat satu garis lurus diagonal. Hasil plotting data residual yang dibandingkan dengan garis diagonal menunjukkan data yang digunakan dalam penelitian ini dapat dikatakan normal.

Uji autokorelasi dilakukan untuk mengetahui sejauh mana korelasi antara data yang diurutkan menurut waktu baik secara deret waktu atau dalam cross section. Dalam 
konsep regresi, model regresi linear klasik mengasumsikan bahwa tidak terdapat autokorelasi. Menurut (Ghozali, 2012) tidak ada gejala autokorelasi jika nilai Durbin Watson terletak antara du sampai dengan 4du. Dalam penelitian ini menggunakan Uji Durbin Watson untuk $\mathrm{n}=186$ dan $\mathrm{k}=3$ (banyakan variable independent) diketahui nilai du sebesar 1,7910 dan 4-du sebesar 2,209 . Hasil pengujian autokorelasi dapat dilihat pada tabel 4 diperoleh hasil uji Durbin Watson sebesar 1,952 yang terletak diantara 1,7910 dan 2,209, maka dapat disimpulkan bahwa asumsi tidak terdapat autokorelasi telah terpenuhi.

Tabel 4. Uji Autokorelasi Durbin Watson

\begin{tabular}{cc}
\hline Model & Durbin-Watson \\
\hline 1 & 1,952 \\
\hline Sumber : Data primer diolah (2019)
\end{tabular}

Uji Multikolinieritas dilakukan untuk mengetahui bahwa tidak terjadi hubungan yang sangat kuat atau tidak terjadi hubungan linear yang sempurna atau dapat pula dikatakan bahwa antar variabel bebas tidak saling berkaitan. Tidak terjadi gejala multikolinieritas jika nilai tolerance $>0,1$ dan nilai VIF<10,0 (Ghozali, 2012).

Tabel 5. Hasil Uji Multikolinieritas

\begin{tabular}{ll}
\hline \multicolumn{1}{c}{ Variabel Bebas } & Sig. \\
\hline Usability & 0,292 \\
Information Quality & 0,387 \\
Service Interaction Quality & 0,324 \\
\hline
\end{tabular}

Sumber : Data primer diolah (2019)

Berdasarkan tabel 5 diatas ketiga variabel bebas dalam penelitian ini memenuhi syarat yaitu nilai tolerance untuk variabel usability sebesar (0,350), nilai variabel information quality sebesar $(0,279)$, dan variabel service interaction sebesar $(0,356)$ lebih besar dari 0,1 dan dapat disimpulkan bahwa tidak terjadi multikolinieritas antara variabel independen.

Uji Heterokedastisitas digunakan untuk mengetahui apakah terjadi ketidaksamaan nilai simpangan residual akibat besar kecilnya nilai salah satu variabel bebas atau independen. Salah satu cara untuk menguji heterokedastisitas aadalah dengan mengunakan Uji Glejser. Berikut ini merupakan hasil Uji Glejser dengan menggunakan SPSS Versi 23 :

Tabel 6. Hasil Uji Glejser

\begin{tabular}{|c|c|c|}
\hline \multirow{2}{*}{ Model } & \multicolumn{2}{|c|}{ Colinearity Statistics } \\
\hline & Tolerance & VIF \\
\hline Usability & 0,350 & 2,854 \\
\hline Information Quality & 0,279 & 3,581 \\
\hline Service Interaction & 0,356 & 2,811 \\
\hline
\end{tabular}

Sumber : Data primer diolah (2019)

Berdasarkan tabel 6 di atas diketahui bahwa pada masing-masing variabel diperoleh nilai sig. >0,05 maka disimpulkan tidak terjadi heteroskedastisitas. Atau dengan kata lain asumsi non-heteroskedastisitas yang diuji telah terpenuhi syaratnya.

\section{Uji Hipotesis dan Regresi Linear Berganda}

Berikut ini merupakan hasil uji hipotesis dan Regresi Linear Berganda dengan menggunakan 3 variabel independen yang diwakili oleh usability (X1), information quality (X2), dan service interaction quality (X3) serta variabel dependen diwakili oleh variabel kepuasan pengguna (Y).

Tabel 7. Hasil Uji F

\begin{tabular}{lcccc}
\hline \multicolumn{1}{c}{ Model } & $\begin{array}{c}\text { Sum of } \\
\text { Squares }\end{array}$ & df & $\begin{array}{c}\text { Mean } \\
\text { Square }\end{array}$ & F \\
\hline Regression & 1132,742 & 3 & 377,581 & 179,45 \\
Residual & 378,736 & 180 & 2,104 & \\
Total & 151,478 & 183 & & \\
\hline
\end{tabular}

Sumber : Data diolah (2019)

Pada tabel 7 dapat dilihat nilai $F_{\text {hitung }}$ sebesar 179,451 lebih besar dari nilai $\mathrm{F}_{\text {tabel }}(\alpha$ $=0,05 ; \mathrm{db}$ regresi $3 ; \mathrm{db}$ residual 180$)$ adalah sebesar 1,968 atau jika dilihat dari nilai Sig. F $(0.000)<\alpha=0,05$ maka dapat disimpulkan bahwa secara simultan ketiga variabel independen berpengaruh terhadap kepuasan pengguna. Hal ini berarti model penelitian regresi yang digunakan dalam penelitian ini layak digunakan. 
Tabel 8. Hasil Uji $\mathrm{T}$ dan Regresi Linear Berganda

\begin{tabular}{|c|c|c|c|c|}
\hline \multirow{2}{*}{ Model } & \multicolumn{2}{|c|}{$\begin{array}{c}\text { Unstandardized } \\
\text { Coefficients }\end{array}$} & \multirow{2}{*}{$\mathrm{t}$} & \multirow{2}{*}{ Sig. } \\
\hline & B & $\begin{array}{l}\text { Std. } \\
\text { Error }\end{array}$ & & \\
\hline (Constant) & 1,196 & ,769 & 1,556 &, 121 \\
\hline Usability &, 115 & ,046 & 2,497 & 013 \\
\hline Information & & & & \\
\hline Quality & ,278 &, 057 & 4,864 &, 000 \\
\hline Service Interaction & & & & \\
\hline Quality & ,389 &, 056 & 6,941 &, 000 \\
\hline$R$ & ,866 & & & \\
\hline$R$ Square & ,749 & & & \\
\hline Adjusted R Square &, 745 & & & \\
\hline
\end{tabular}

Sumber : Data primer diolah (2019)

Berdasarkan hasil Uji T pada tabel 8 di atas didapatkan persamaan regresi : $\mathrm{Y}=$ $1,196+0,115 \mathrm{X} 1+0,278 \mathrm{X} 2+0,389 \mathrm{X} 3$. Pada tabel 8 menunjukkan hasil t hitung untuk variabel usability sebesar 2,497, variabel information quality sebesar 4,864, dan variabel service interaction quality sebesar 6,941 lebih besar dari t tabel sebesar 1,96 atau jika dilihat dari nilai signifikansinya $<\alpha=0,05$ maka dapat disimpulkan secara parsial ketiga variabel tersebut signifikan mempengaruhi kepuasan pengguna.

Pada tabel 8 juga menunjukkan hasil pengujian koefisien determinasi atau $\mathrm{R}_{\text {Square }}$ dengan nilai yang diperoleh sebesar 0,866 . Nilai ini dapat diartikan bahwa variabel independen pada penelitian ini mampu mempengaruhi dan menjelaskan variabel dependen yakni kepuasan pengguna sebesar 86,6\%, sedangkan sisanya sebesar 13,4\% dipengaruhi dan dijelaskan oleh variabel lain yang tidak diteliti dalam penelitian ini.

\section{Pengaruh Usability $\left(\mathrm{X}_{1}\right)$ terhadap Kepuasan Pengguna (Y)}

Hasil penelitian yang telah dilakukan membuktikan bahwa variabel independen yaitu usability berpengaruh positif signifikan terhadap kepuasan pengguna Traveloka. Hal ini dapat diartikan bahwa dengan semakin meningkat kemudahan (usability) para pengguna Traveloka maka akan meningkatkan kepuasan pengguna karena pengguna merasa terbantu dengan kemudahan tersebut.. Penjelasan ini sejalan dengan (Liang \& Chen, 2009) mengungkapkan usability website merupakan kemudahan pengguna dalam memproses dan mengakses ketersediaan, fleksibilitas, keandalan, dan waktu respons. Temuan hasil penelitian ini diperkuat (Muhsin \& Zuliestiana, 2017) menyatakan usability memberikan rasa kepuasan terhadap para pengunjung situs yang sedang diteliti. Rasa puas muncul ketika kualitas website yang dikunjungi memenuhi persepsi dan harapan user atau pengguna.

\section{Pengaruh Information Quality terhadap Kepuasan Pengguna (Y)}

Hasil penelitian ini menunjukkan bahwa variabel information quality berpengaruh positif signifikan terhadap kepuasan pengguna Traveloka. Hal ini dapat diartikan bahwa semakin baiknya information quality maka semakin tinggi kepuasan pengguna karena para user pengguna Traveloka menilai pihak Traveloka telah memberikan informasi yang akurat, format, relevan dan update sesuai dengan yang diinginkan oleh user sebagai penggunanya. Temuan ini diperkuat oleh (Khai, 2018) menjelaskan bahwa kualitas informasi sebuah website tidak hanya memberikan rasa puas kepada pengguna, tetapi juga memberikan keloyalan pengguna terhadap situs yang diakses. Semakin baik kualitas informasi yang dimiliki oleh sebuah website semakin tinggi tingkat kepuasan yang dirasakan oleh pengguna website tersebut.

\section{Pengaruh Service Interaction Quality ( $\left.\mathbf{X}_{3}\right)$ terhadap Kepuasan Pengguna (Y)}

Berdasarkan hasil penelitian menunjukkan bahwa variabel service interaction berpengaruh secara positif signifikan terhadap kepuasan pengguna Traveloka. Hal ini memiliki arti bahwa dengan semakin meningkatnya service interaction yang diberikan oleh manajemen 
Traveloka, maka semakin meningkat kepuasan pengguna karena user merasa dapat berinteraksi secara mendalam. Interaksi tersebut meliputi rasa aman saat bertransaksi, memiliki reputasi yang baik, kemudahan komunikasi, menciptakan rasa kepercayaan akan hal-hal yang bersifat pribadi, dan memberikan jaminan terkait ketepatan janji. Hal ini sejalan temuan (Manasra, Zaid, \& TaherQutaishat, 2013) menjelaskan bahwa salah satu hal yang terpenting dalam memenuhi rasa puas seorang pengguna adalah bentuk interaksi layanan yang diberikan oleh penyedia website. Temuan hasil penelitian ini juga diperkuat (Ardi \& Yulisetiarini, 2018) dengan adanya interaksi yang baik memberikan pengaruh yang baik kepada pengguna.

\section{Kesimpulan}

Berdasarkan hasil penelitian, analisis data dan pembahasan yang telah dilakukan dapat disimpulkan beberapa hal sebagai berikut : 1) Usability memiliki pengaruh positif dan signifikan terhadap kepuasan pengguna Traveloka. Ini berarti semakin tinggi usability pada website Traveloka maka semakin tinggi kepuasan yang dirasakan oleh para pengguna Traveloka. Hal tersebut didasari akan kemudahan yang diberikan pihak manajemen dalam tampilan interface dan kemudahan dalam sistem pengoperasian; 2) Information quality memiliki pengaruh positif dan signifikan terhadap kepuasan pengguna Traveloka. Semakin handal informasi yang diberikan dan dapat dipercaya maka kepuasan pengguna website Traveloka akan meningkat; Hal tersebut didasari akan kemampuan yang dimiliki manajemen Traveloka dalam memberikan informasi yang benar dan akurat, menyajikan informasi yang mampu memenuhi kebutuhan pengguna dan dapat dipertanggungjawabkan; dan 3) Service interaction memiliki pengaruh positif dan signifikan terhadap kepuasan pengguna Traveloka. Semakin baik interaksi yang bisa dijalin maka kepuasan pengguna website Traveloka akan meningkat $\mathrm{Hal}$ ini didasari akan kemampuan manajemen traveloka dalam beriteraksi dengan pengguna dengan memberikan rasa aman, nyaman dan mampu menjaga informasi pengguna yang bersifat pribadi serta menjamin janji-janji yang diberikan untuk direalisasikan.

\section{DAFTAR PUSTAKA}

Ardi, A. N. A., \& Yulisetiarini, D. (2018). The Effect of Lazada Website Quality to Satisfaction and Consumer Loyalty. 5.

Ariani, D. Orothea W. (2009). Manajemen Operasi Jasa (1st Ed.). Yogyakarta: Graha Ilmu.

Asosiasi Penyelenggara Jasa Internet Indonesia. (2018, December). Retrieved From Https://Apjii.Or.Id: Https://Apjii.Or.Id/Survei2018

Barnes, S. J., \& Vidgen, R. T. (2002). An Integrative Approach To The Assessment of E-Commerce Quality. (August 1998), 114-127.

Behera, J. P. (2018). Impact of Service Quality on Customer Loyalty In Indian Banking Sector In Odisha. (June).

Https://Doi.Org/10.18231/2454-

9150.2018.0165

Cooper, P, Schindler, S. (2014). Metode Riset dan Bisnis (Budijanto, D. Djunaedi, D. Sihombing \& Penerjemah, Trans. 9 Ed). Jakarta: Pt. Media Global Edukasi.

Ghozali, I. (2012). Aplikasi Analisis Multivariate Dengan Program Ibm Spss 20. Undip: Semarang.

Hair, J. F., Black, W. C., Babin, B. J., \& Anderson, R. E. (2014). Multivariate Data Analysis (7th Edition). Pearson Education Limited.

Hsu, C., Chang, K., \& Chen, M. (2012). and

Purchase Intention: Perceived Playfulness and Perceived Flow as Mediators. (313), 549-570. Https://Doi.Org/10.1007/S10257011-0181-5

Hsu, C.-L., Chang, K.-C., \& Chen, M.-C. (2012). The Impact of Website Quality on Customer Satisfaction and Purchase Intention: Perceived 
Playfulness and Perceived Flow As Mediators. Information Systems And E-Business Management, 10(4), 549570.

Https://Doi.Org/10.1007/S10257-

$$
\text { 011-0181-5 }
$$

Khai, N. T. N. (2018). The Effects of Website Quality on Customer Satisfaction and Loyalty to Online Travel Agencies In Vietnam. 15.

Kotler, Philip, Amstrong, G. (2008). PrinsipPrinsip Pemasaran (Jilid 1). Jakarta: Erlangga.

Liang, C.-J., \& Chen, H.-J. (2009). A Study of The Impacts of Website Quality on Customer Relationship Performance. Total Quality Management \& Business Excellence, 20(9), 971-988. Https://Doi.Org/10.1080/1478336090 3181784

Lovelock, C. \& L. W. (2007). Manajemen Pemasaran Jasa. Jakarta: PT Indeks.

Manasra, E. A.-, Zaid, "Mohammed Khair" Saleem Abu, \& Taherqutaishat, F. (2013). Investigating The Impact Of Website Quality On Consumers' Satisfaction In Jordanian Telecommunication Sector. Arab Economic And Business Journal, 8(1-2), 31-37. Https://Doi.Org/10.1016/J.Aebj.2013. 11.004

Muhsin, A., \& Zuliestiana, D. A. (2017). Analisis Pengaruh Kualitas Website (Webqual) 4.0 Terhadap Kepuasan Pengguna Bukalapak Di Kota Bandung. 10.

Noronha, A. K., \& Rao, P. S. (2017). Effect of Website Quality On Customer Satisfaction And Purchase Intention In Online Travel Ticket Booking Websites. $\quad 7(5), \quad$ 168-173. Https://Doi.Org/10.5923/J.Mm.20170 705.02

Raharjo, B. (2011). Belajar Pemograman Web. Bandung: Modula.

Tatang, M. (2017). The Impact of Website Design Quality, Service Quality, and Enjoyment On Repurchase
Intention Through Satisfaction and Trust at Zalora. 6, 1-11.

Tjiptono, A. (2017). Service Management (Edisi 3). Yogyakarta: Andi. 